\begin{tabular}{lllll}
\hline Motrivivência & Ano XX, & No 31, P. 241-250 & Dez./2008 \\
\hline
\end{tabular}

\title{
Articulações Entre Lazer e Mídia na Educação Física Escolar
}

Diego S. Mendes'

\begin{abstract}
Resumo
O presente trabalho trata-se de um relato de experiência que buscou tematizar o lazer em uma escola pública de Florianópolis a partir da produção de vídeos com os alunos.

Os objetivos foram: a) Identificar estratégias didático-metodológicas para Educação Física escolar tratar do conteúdo lazer em suas aulas; b) Verificar os limites e possibilidades de tematização do lazer em aulas de Educação Física a partir do uso das Tecnologias de Informação e Comunicação (Tic's). O estudo foi desenvolvido a partir do referencial metodológico da Pesquisa-Ação e de apontamentos conceituais da mídiaeducação e da lazerania.
\end{abstract}

Palavras-Chaves: Lazer; MídiaEducação; Educação Física

\begin{abstract}
This report presents the leisure like a contend of the Physical Education in a public school from Florianópolis, producing videos with the students. The objectives were: a) Identify strategies didactic-methodological to the Physical Education teaching the contents leisure in the classes, b) Check the limits and possibilities of the Communication and Information Technology in the physical education classes. The study is an Action-Research and uses media-education and lazerania conceptual notes.
\end{abstract}

Keywords: leisure; media-education; physical education

1 Mestre em Educação Física pelo PPGEF/UFSC; professor do DEF/UFS; pesquisador do LaboMidia/ UFSC-UFS. 


\section{Introdução}

O presente trabalho é resultado/expressão da realização de um curso de formação contínua de professores de Educação Física realizado em Florianópolis -SC, a partir de parceria estabelecida entre o Laboratório de Mídia do Centro de Desportes da Universidade Federal de Santa Catarina (LaboMídia/ UFSC) e a Secretaria Municipal de Educação (S.M.E.). O referido curso foi denominado de Oficina de Mídia-Educação \& Educação Física e teve como objetivo incentivar o uso de novas tecnologias de informação e comunicação (Tic's) nas escolas numa perspectiva educativa ${ }^{2}$.

Ao final da oficina cada professor participante formulou uma proposta de interlocução ${ }^{3}$ escolar com o tema da mídia e/ou uso das Tic's para serem levadas as aulas de Educação Física. O presente trabalho visa a descrever/ investigar uma destas propostas de interlocução escolar, que no caso propôs a tematização do lazer em uma escola pública de florianópolis, envolvendo a produção de vídeos com os alunos. neste contexto, propusemos um estudo a partir do seguinte problema de pesquisa: Quais os limites e possibilidades de tematização do lazer em aulas de Educação Física a partir do uso das Tecnologias de Informação e Comunicação (Tic's)?

Os objetivos do trabalho foram: a) Identificar estratégias didático-metodológicas para tratar do conteúdo lazer no âmbito da Educação Física escolar; b) Verificar os limites e possibilidades de tematização do lazer em aulas de Educação Física a partir do uso das Tic's.

\section{Alguns elementos teórico- metodológicos do estudo}

\subsection{A Lazerania como possi- bilidade ampliada para abor- dagem do lazer na Educação Física escolar}

A perspectiva da lazerania apontada por Mascarenhas (2004) tem como preocupação central localizar o lazer no escopo mais amplo das transformações sociais em curso no mundo do trabalho, centrando-se nas determinações que atravessam a esfera política,

2 A proposta de capacitação aqui descrita integrava pesquisa que resultou em dissertação de mestrado apresentada no PPGEF/UFSC (MENDES, 2008), orientada pelo professor Giovani De Lorenzi Pires.

3 O termo interlocução escolar foi adotado neste trabalho em oposição a idéia de intervenção (termo mais freqüente no linguajar dos professores). Entende-se aqui, conforme sugere Betti (2006), que o termo intervenção carrega, na prática pedagógica, uma conotação autoritária. 
especialmente, aquelas relativas à desintegração dos direitos sociais, em que o lazer pode se prestar à educação/formação para a cidadania. Segundo o autor,

A idéia de "lazerania", ao mesmo tempo em que procura expressar a possibilidade de apropriação do lazer como um tempo e espaço para a prática da liberdade, isto é, para o exercício da cidadania, busca traduzir a qualidade social e popular de uma sociedade cujo direito ao lazer tem seu reconhecimento alicerçado sobre princípios como planificação, participação, autonomia, organização, transformação, justiça e democracia, deixando de ser monopólio ou instrumento daqueles que concentram o poder econômico. (MASCARENHAS, 2004. p. 74-75)

Neste âmbito, o conteúdo lazer não é entendido apenas em sentido estrito, como um bem em sí próprio, ao contrário, a lazerania considera o tema em suas inter-relações com as condições históricas, sociais e políticas do contemporâneo, bem como sua relação no contexto de produção capitalista. $\mathrm{O}$ conteúdo lazer assume características mais amplas e desafiadoras, para além de uma perspectiva frívola, de manutenção da lógica produtivista e reificadora do capital. Assume-se, portanto, que o trato com o lazer no âmbito educativo deve tencionar os nexos causais que arrogam este objeto à forma de mercadoria.

O objetivo, neste caso, consiste em buscar consolidar no âmbito do lazer um espaço significativo de formação para a cidadania, especialmente no que toca a mobilização popular e conscientização de classe rumo a uma nova direção política, ao diálogo com saberes, habilidades, métodos, estratégias, experiências dos sujeitos sociais, a fim de que estes reivindiquem direitos, reconheçam determinações e reclamem transformações no tocante a esfera do lazer público. Isto implica em um projeto de esclarecimento crítico em relação aquilo que Horhkeimer e Adorno (1997) classificaram como uma domesticação cultural do tempo livre, devido à consolidação da indústria cultural.

Neste bojo, a produção capitalista da cultura "tem a função de ocupar o espaço de lazer que resta ao operário e ao trabalhador assalariado depois de um longo dia de trabalho, a fim de recompor suas forças para voltar a trabalhar no dia seguinte sem lhe dar trégua para pensar sobre a realidade miserável em que vive" (FREITAG, 1990. p.72).

Portanto, considerando-se este contexto, o que se procura con- 
solidar são práticas de lazer autênticas, desvinculadas das perspectivas individualizantes e entretenimentista. Nestes termos, a construção da lazerania se daria pelo exercício de uma práxis educativa em que se considere o lazer como possibilidade de esclarecimento crítico do "mercolazer", orientando-se pelos interesses populares autônomos e pela organização social em prol de melhores condições cidadãs.

\subsection{A perspectiva educacio- nal da Mídia-Educação}

Sem dúvida a percepção humana se alterou com o advento das Tic's. Isto, no entanto, não significou que a capacidade humana de acompanhar a realidade se ampliou, ao contrário, o vasto referencial produzido pelos autores da Escola de Frankfurt ${ }^{4}$, entre outros, alegam que tal competência se diluiu com a consolidação das comunicações de massa.

As gerações imersas na cultura midiática dificilmente percebem os problemas ou as implicações destas tecnologias sobre si próprias. Este é um dos motivos que tem mobilizado à escola o papel de problematizar a mídia e de formar leitores críticos dos meios de comunicação de massa. As evidências levantadas por diferentes autores são enfáticas na constatação de que os veículos de comunicação de massa participam em grande escala da formação das gerações atuais. Isto porque, é fato, que as horas dispensadas a tais veículos, seja intencionalmente ou não, ocupam grande parte, se não, a maior parte, do tempo presente.

Neste sentido, é importante que os recursos de resistência e de ressignificação das mensagens midiáticas sejam fomentados via educação, pois, munidos da capacidade de leitura e interpretação crítica dos meios, os indivíduos terão cada vez mais aportes para aumentar sua autonomia em relação ao modo de conviver em ambiente tão sedutor. Esta é a perspectiva da Mídia-Educação sugerida por autores como Belloni (2001) e Fantin (2006), da retomada da mídia como possibilidade para uma educação crítica, que vise a promoção de uma cidadania esclarecida em relação aos discursos e possibilidades da tecnologia de informação e comunicação contemporânea. Segundo Fantin (2006), o que se tem proposto é que a escola utilize

4 A Escola de Frankfurt refere-se a um grupo de estudiosos do Instituto para Pesquisa Social de Frankfurt (Institut für Sozialforschung) da Universidade de Frankfurt-am-Main na Alemanha, onde se desenvolveu a chamanda Teoria Crítica. Entre os estudiosos da Escola de Frankfurt pode-se destacar Marcuse, Adorno, Horkheimer e Benjamin. 
a mídia como uma possibilidade de diálogo crítico e criativo com a cultura da mídia, utilizando-a na forma de expressão e produção cultural, como objeto de análise e reflexão sobre seus produtos, mensagens e discursos.

\subsection{A Pesquisa-Ação Como Guia Metodológico}

O presente trabalho se respalda em elementos teórico-metodológicos da pesquisa-ação, caracterizada por Elliot (1998) como um tipo de pesquisa educativa em que os próprios pesquisadores examinam criticamente o contexto e/ou o fato pesquisado, a partir de sua inserção nas situações pesquisadas, situando-se ao mesmo tempo como pesquisadores e participantes do estudo.

A pesquisa-ação não se fundamenta na idéia de experimentação isolada, em que o pesquisador se mantém neutro e/ou autônomo em relação à realidade social; sua perspectiva centra-se em visualizar de maneira integrada conhecimento e intervenção (FRANCO, 2005).

\section{Relato da experiência: lazer e mídia na educação física}

O estudo foi desenvolvido em uma escola pública da rede municipal de Florianópolis, em parce- ria com mais quatro professoras da instituição, entre elas, uma professora de Educação Física, uma professora regente de sala de aula, a coordenadora da sala informatizada da escola e a coordenadora da biblioteca. O período de realização da interlocução ENTRE novembro E dezembro/2007, SENDO o trabalho desenvolvido com uma turma de $3^{\mathrm{a}}$ série DO ENSINO FUNDAMENTAL.

A coleta dos dados da pesquisa foi realizada a partir de Observação Participante de toda a experiência de interlocução escolar, com registro em Diário de Campo, complementada pela realização de uma Entrevista em Grupo ou Grupo Focal com as professoras participantes ao final do processo. O tratamento dos dados foi realizado a partir de validação descritiva do material junto às professoras e análise de conteúdo dos dados (Bardin,1977).

A interlocução escolar que visou tematizar o lazer Na Educação Física, na perpsectiva da mídiaeducação se iniciou com atividades que consistiam em aproximar as crianças aos dois conceitos centrais: lazer e mídia. as ações pedagógicas empreendidas neste sentido valeram-se principalmente da realização de pesquisa bibliográfica com os alunos na internet e na biblioteca da escola, além da realização de vivência de práticas de lazer. O 
objetivo das atividades foi elaborar um conceito de lazer criado pelas próprias crianças. Concomitante à realização dessas atividades foi proposto aos alunos a produção de um vídeo sobre o assunto, o que foi recebido com bastante entusiasmo pelos alunos.

Nas aulas de Educação Física foram promovidas vivências que confrontavam o conteúdo esportivo tradicional e espetacularizado pela mídia (a partir das regras oficiais, com ênfase nas comparações objetivas e sobrepujança física) ao esporte associado à perspectiva do lazer (com possibilidades de elaboração/ transgressão das regras, ênfase na dimensão lúdica em detrimento da competitividade exacerbada, etc.). Com isto, as crianças puderam perceber as diferenças conceituais existentes entre o esporte de rendimento (ligado à esfera do trabalho) e o lazer de forma prática, pelo confronto entre as vivências, além de refletirem sobre o processo de espetacularização dos esportes e do lazer pela mídia. Complementarmente, nas demais disciplinas, as atividades de português, matemática, geografia e história foram associadas ao tema do lazer. Estas atividades transcorreram horizontalmente todo o projeto.

As pesquisas realizadas pelas crianças sobre o lazer na perspectiva da lazerania revelaram que na comunidade em que a escola residia não havia nenhuma área de lazer pública. Esta problemática tornou-se o tema para a produção do vídeo dos alunos e exigiu, num segundo momento, uma preparação específica, com momentos de ensino dedicados a utilização da filmadora, elaboração de roteiro, etc. Diferentes estratégias foram utilizadas para ensinar os alunos a filmarem, entre elas atividades de registros das aulas de Educação Física, produção de pequenas reportagens sobre a escola, entre outras. As crianças também foram divididas em grupos, cada qual com uma tarefa específica na produção do vídeo. Uns seriam repórteres, outros ficaram responsáveis por filmar, outros seriam fotógrafos, etc. Essa dinâmica organizou a tarefa de produção do vídeo. No roteiro foram previstas saída de campo com os alunos, para a elaboração de reportagens que denunciassem a ausência das áreas de lazer na comunidade, além da realização de entrevista com a associação de moradores do bairro (A. M. B.) na busca por soluções ao problema.

As saídas de campo compuseram momentos singulares para as vivências de lazer com as crianças, pois foram visitadas áreas públicas das comunidades vizinhas, além de alguns espaços da comunidade que estavam destinados a 
construção de espaços públicos de lazer. As saídas de campo foram registradas pelos alunos com uso da filmadora e foram compostas pequenas reportagens.

Ao final do projeto, os estudantes realizaram uma entrevista com a presidente da A.M.B., em que foram esclarecidos quais os objetivos da associação e suas formas de atuação, além de questionamentos a respeito dos terrenos do bairro destinados à construção de áreas de lazer. A entrevistada deixou evidente que a participação das crianças seria importante para a conquista de áreas de lazer na comunidade e sugeriu que vídeo produzido por elas fosse entregue à A. M. B., para ser utilizado como um instrumento reivindicatório junto à prefeitura da cidade, uma vez que os projetos para áreas públicas de lazer na comunidade estavam abandonados.

Por fim, as crianças elaboraram um roteiro para o vídeo, a partir das imagens coletadas pelos alunos e, em parceria com o LaboMidia/UFSC, foi realizada a edição do vídeo dos alunos. Todas as decisões do processo foram tomadas pelas crianças, desde a seqüência das cenas, imagens e textos até a escolha das músicas e dos efeitos. O filme das crianças foi concluído e apresentado na escola para o restante da turma, além de ser entregue uma cópia a A.M.B. como documento reivindicatório dos estudantes por possibilidades (espaços, equipamentos, ações) de lazer na comunidade.

\section{Análise, interpretações e reflexões dos dados}

Os dados do trabalho permitiram identificar que a tematização do conteúdo lazer na perspectiva da lazerania (MASCARENHAS, 2004) na escola pode ser facilitada quando associada ao uso das Tic's por tornar a aprendizagem mais lúdica e, em alguma medida, mais inovadora, além de tecer nexos com os sentidos sociais partilhados sobre o lazer. $\mathrm{O}$ que se quer dizer com isto é que, ao associar o desenvolvimento do tema lazer na escola a partir da produção de um vídeo, necessariamente é preciso se aproximar dos sentidos socialmente partilhados sobre lazer na mídia. Para produzirem um vídeo sobre lazer, os alunos precisaram compreender os significados deste quando veiculado em diferentes mídias, como a internet, televisão etc. Partindo dos sentidos socialmente partilhados foi possível às crianças identificar, tanto nas informações coletadas quanto nas vivências práticas, aqueles conteúdos do lazer que se apresentavam em sentido mercadológico, como um bem 
marcado pelo valor-de-troca, como aqueles conteúdos de interesse popular, autônomos aos interesses do modo de produção capitalista.

Outro ponto positivo que identificamos no trabalho foi que a associação da tematização do conteúdo lazer com o uso das Tic's possibilitou o confronto com a realidade extra-escolar, o que facilita o estabelecimento de inter-relações com as condições históricas, sociais e políticas do contemporâneo no que se refere à situação atual do lazer. A produção do vídeo pelos alunos exigiu as saídas de campo para realização de reportagens sobre os espaços de lazer na comunidade. Esta atividade permitiu uma tomada de consciência sobre a ausência destes no bairro da escola, o que também possibilitou ao trabalho um direcionamento a compreensão das possibilidades de superação desta condição.

[...] foi muito legal o vídeo, porque ele fez a gente, assim, sair da escola. Ir além dos muros dela. Aí deu para os guris verem como é o lazer aqui no bairro. Não existe. Eu sempre achei que essas coisas que a gente ensina têm que ter, sabe, uma ligação com o mundo aí fora mesmo. (Relato da Prof. de Educação Física no grupo Focal.)

Esta foi à situação por excelência que articulou o desen- volvimento do conteúdo lazer com a possibilidade de formação cidadã dos alunos, uma vez que atribuiu um caráter político explícito ao trabalho, quer seja, de direcionar a produção do vídeo para a denúncia daquela situação. Aqui podemos afirmar que o trabalho passou a se alinhar mais concretamente com a perspectiva da lazerania, visto que, como coloca Mascarenhas (2004, p. 75), a apropriação do lazer foi vista "como um tempo e espaço para a prática da liberdade, isto é, para o exercício da cidadania, busca traduzir a qualidade social e popular de uma sociedade cujo direito ao lazer tem seu reconhecimento".

Os alunos participantes da interlocução puderam, assim, aprender na aula de Educação Física não apenas brincadeiras, ou atividades lúdicas, o que em alguma medida se tornou lugar comum das práticas que dizem tratar da temática do lazer na escola. Ao contrário, junto com as práticas de atividades de lazer os alunos tiveram a oportunidade de se apropriar de conceitos sobre lazer, sistematizar esse conteúdo em forma de vídeo e ainda exercitar a cidadania na busca de soluções para o problema da ausência de espaços de lazer na comunidade, conforme identificado no trabalho.

Nesta direção, os alunos aprenderam sobre as formas de organização populares para reivin- 
dicação de diretos junto ao poder público. A principal atividade nesse sentido foi à realização de uma entrevista com a associação de moradores do bairro, em que os alunos buscaram investigar exatamente o que era essa organização e como ela já havia conquistados direitos públicos para comunidade. Os alunos produziram uma carta, em uma atividade interdisciplinar com a professora de português, dirigida ao poder público da cidade, apresentando as reivindicações para a solução do problema da ausência de espaços de lazer no Bairro.

A dimensão lúdica do trabalho também merece destaque, conforme aponta a seguinte passagem do diário de campo de pesquisa:

Até as atividades mais técnicas, como aprender a filmar se transformaram logo em jogo imaginativo. As crianças saiam brincando de repórteres, encenando aventuras ou lances mágicos do futebol para que outros colegas, também com suas câmeras imaginárias, registrassem os lances espetaculares (Registro em diário de campo do pesquisador - 12/11/2006).

\section{Reflexões finais}

O trabalho permitiu avaliar de maneira coesa que a mídiaeducação, ao contrário do que se pode afirmar à primeira vista, não descaracteriza a aula de Educação Física. Se, por um lado, há o receio na área de que a mídia-educação reduza a aula de Educação Física a um discurso sobre a prática ou sobre a televisão, de outro lado constatou-se que as atividades com a filmadora, ou em sala de aula não se constituíram como obstáculos à aula de Educação Física, que apenas se complementou com essas atividades.

Quanto à mídia-educação enquanto eixo metodológico-didático pode-se dizer que esta deve estar inserida na Educação Física escolar no desenvolvimento de um tema específico, como o lazer, por exemplo, tal como sugeriu a pesquisa realizada por Betti (2006) e em interlocuções coletivas, enquanto um tema transversal. É o que indicaram os professores que tiveram oportunidade de realizar as interlocuções escolares.

É, para trabalhar mídia tem que ser interdisciplinar, é um tema de toda escola [...] essa cidadania para mídia é tarefa de toda a escola e só dá pra fazer se for junto, se não tu não consegues. Tem também que estar no contexto do tema que a gente vai tratar, se não fica sem sentido, é usar por usar. (Relato da Prof. de Educação Física no grupo Focal).

O estudo também contribuiu com a escola onde foi realizada 
a interlocução escolar, seja por ter possibilitado a realização de experiências sistematizadas com mídia-educação e o tema do lazer, que geraram novos debates e novas reflexões entre alunos, professores e direção a respeito do papel da mídia e do lazer na sociedade contemporânea; seja por ter possibilitado à escola e às professoras uma margem de autonomia para continuarem a trilhar este caminho desafiante com e através da mídia para a formação da cidadania das crianças e jovens deste país.

\section{Referências}

BARDIN, Laurence. Análise de Conteúdo. Lisboa: Edições70, 1977.

BELLONI, Maria Luiza. O Que é Mídia-Educação. $2^{a}$ ed. CampinasSP: Autores associados, 2005.

BETTI, Mauro. "Imagens em Ação": Uma pesquisa-ação sobre o uso de matérias televisivas em programas de educação física do ensino fundamental e médio. Revista MOVIMENTO, v12, n2, p. 95-120, mai/ago. 2006.

ELLIOT, John. Recolocando a pesquisa-ação em seu lugar original e próprio. In: GERALDI, C. M. G.; FIORENTINI, D.; PEREIRA, E. M. A. (Orgs.). Cartografias do trabalho docente. Campinas: Mercado da Letras, 1998, p. 137-152.
FANTIN, Mônica. Mídia-Educação: Conceitos, experiências, diálogo Brasil-Italia. Florianópolis: Cidade Futura, 2006.

FRANCO, Maria Amélia Santoro. Pedagogia da Pesquisa-Ação. Educação e Pesquisa, São Paulo, v. 31, n. 3, p. 483-502, set./dez. 2005Bardin (1977).

FREITAG, Bárbara. A Teoria Critica: ontem e hoje. São Paulo: Brasiliense, 1990.

HORKHEIMER, Max; ADORNO, Theodor. W. Dialética do Esclarecimento: Fragmentos filosóficos. Rio de Janeiro: Jorge Zahar, 1997.

HORKHEIMER, Max; ADORNO, Theodor. W. Dialética do Esclarecimento: Fragmentos filosóficos. Rio de Janeiro: Jorge Zahar, 1997.

MASCARENHAS, Fernando. "Lazerania" também é conquista: tendências e desafios na era do mercado. Revista Movimento, Porto Alegre, v. 10, n. 2, p.7390, maio/agosto de 2004.

MENDES, Diego S. LUZ, CÂMERA E PESQUISA-AÇÃO: a inserção da mídia-educação na formação contínuadeprofessoresdeEducação Física. Dissertação (Mestrado em Educação Física). Florianópolis: PPGEF/UFSC, 2008.

Recebido: 14/fevereiro/2010. Aprovado: 26/abril/2010. 